Adsor pt i on behavi or of nat ural ant hocyani $n$ dye on mesopor ous si I i ca

\begin{tabular}{|c|c|}
\hline 著者 & $\begin{array}{l}\text { Kohno Yoshi umi, Haga Eri ko, Yoda Kei ko, } \\
\text { Shi bat a Masashi, Fukuhar a Choj i, Tomi ta } \\
\text { Yasumasa, Naeda Yasuhi sa, Kobayashi Kenki chi ro }\end{array}$ \\
\hline $\begin{array}{l}\text { journal or } \\
\text { publ i cat i on title }\end{array}$ & Journal of Physi cs and Chemistry of Sol i ds \\
\hline vol une & 75 \\
\hline number & 1 \\
\hline page $r$ ange & 48-51 \\
\hline year & 201401 \\
\hline 出版者 & El sevi er \\
\hline 権利 & $\begin{array}{l}\text { Copyright (C) } 2013 \text { El sevi er Ltd. Al I right s } \\
\text { reserved. }\end{array}$ \\
\hline 注記 & 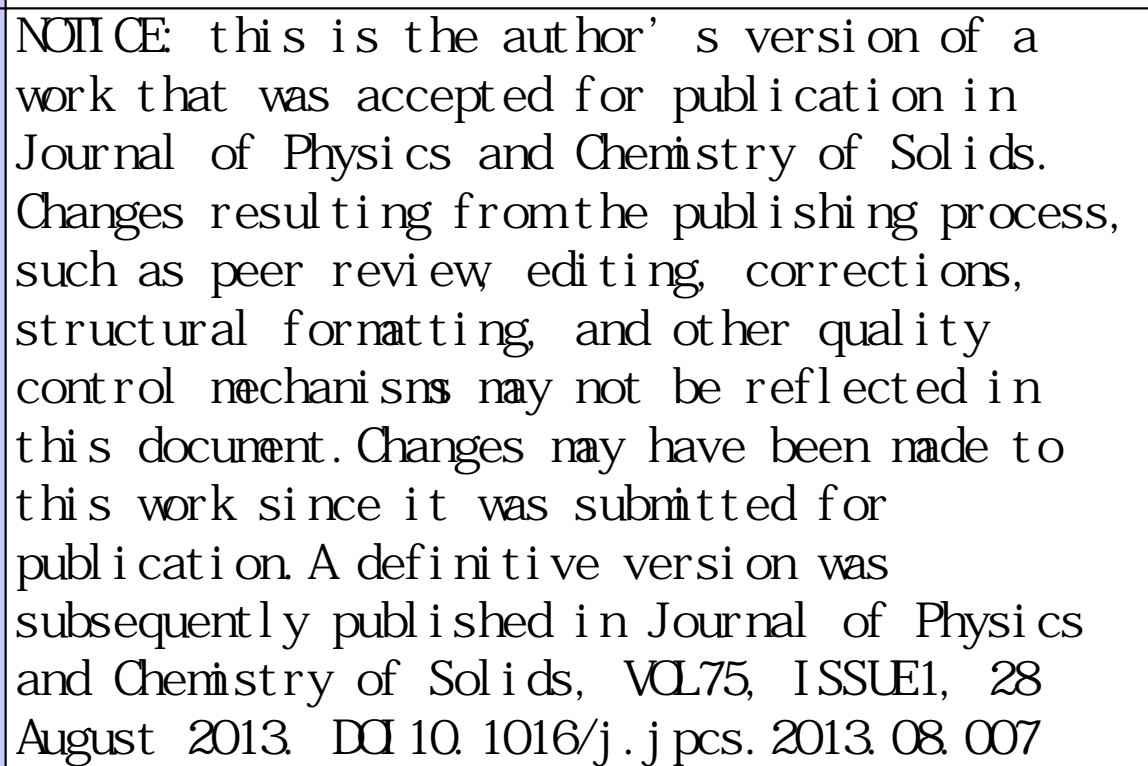 \\
\hline URL & ht t p: //hdl . handl e. net /10297/7627 \\
\hline
\end{tabular}




\title{
Adsorption behavior of natural anthocyanin dye on mesoporous silica
}

Yoshiumi Kohno ${ }^{a}$, Eriko Haga ${ }^{a}$, Keiko Yoda $^{b}$, Masashi Shibata ${ }^{c}$, Choji Fukuhara ${ }^{a}$, Yasumasa Tomita ${ }^{a}$, Yasuhisa Maeda ${ }^{a}$, Kenkichiro Kobayashi $^{a}$

${ }^{a}$ Department of Applied Chemistry and Biochemical Engineering, Graduate School of Engineering, Shizuoka University, 3-5-1, Johoku, Naka-ku, Hamamatsu, Shizuoka 432-8561, Japan

${ }^{b}$ Beauty Research Center, Kao Corporation, 2-1-3 Bunka, Sumida-ku, Tokyo 131-8501, Japan

${ }^{c}$ School of Bioscience and Biotechnology, Tokyo University of Technology, 1404 Katakura, Hachioji, Tokyo 192-0982, Japan

Corresponding author: Yoshiumi Kohno

Department of Applied Chemistry and Biochemical Engineering, Graduate School of Engineering, Shizuoka University, 3-5-1, Johoku, Naka-ku, Hamamatsu, Shizuoka 432-8561, Japan

E-mail: tykouno@ipc.shizuoka.ac.jp, Phone number:+81-53-478-1623

\begin{abstract}
Because of its non-toxicity, naturally occurring anthocyanin is potentially suitable as a colorant for foods and cosmetics. To the wider use of the anthocyanin, the immobilization on the inorganic host for an easy handling as well as the improvement of the stability is required. This study is focused on the adsorption of significant amount of the natural anthocyanin dye onto mesoporous silica, and on the stability enhancement of the anthocyanin by the complexation. The anthocyanin has successfully been adsorbed on the HMS type mesoporous silica containing small amount of aluminum. The amount of the adsorbed anthocyanin has been increased by modifying the pore wall with $n$-propyl group to make the silica surface hydrophobic. The light fastness of the adsorbed anthocyanin has been improved by making the composite with the HMS samples containing aluminum, although the degree of the improvement is not so large.
\end{abstract}


It has been proposed that incorporation of the anthocyanin molecule deep inside the mesopore is required for the further enhancement of the stability.

KEYWORDS: A. microporous materials, A. organic compounds, D. optical properties, D. surface properties. 


\section{Introduction}

Anthocyanins are one of naturally occurring dyes found in many flower petals and fruits $[1,2]$. The structure of the typical anthocyanin is shown in Figure 1. Anthocyanins are non-toxic and used as a colorant of foods and cosmetics [3]. In order to use the anthocyanin more widely, investigations have been made so far in regard to the improvements of the properties of the dye. For the benefit of the ease in handling, and for the increasing affinity to various media, immobilization onto the solid matrices is one of the steps required for the wider practical use of the anthocyanin. In addition, the instability of the anthocyanin is another reason for the limited use: the anthocyanin generally loses its color easily at elevated temperature, neutral to basic $\mathrm{pH}$ conditions, and especially under visible-light irradiation [4]. The enhancement of the color stability is essential for practical use of the anthocyanin [5]. The immobilization of the anthocyanin on the solid host materials is also one promising approach to improve the stability [6-8].

In this study, we try to immobilize the anthocyanin on mesoporous silicates. Since the mesoporous silicates are known to have an overwhelming large surface area, they expectedly have potential to adsorb enough amounts of various organic molecules including dye [9-12]. Among many type of mesoporous silicates, an HMS type one is characteristic of rather mild preparation condition that it can be prepared at room temperature in an aqueous solution using neutral alkyl amines as a structure-directing agent [13]. We have previously reported that Al-containing HMS type mesoporous silica adsorbs sufficient amount of the flavylium, a model synthetic dye having the same molecular skeleton as the natural anthocyanin (Figure 1) [14], and that the incorporated flavylium exhibits enhanced stability against visible light irradiation [15, 16]. It has also been reported by other groups that the incorporation into the mesoporous silicate stabilizes other dye molecules [17-19]. In our case, it has been found that the solid acidity caused by the $\mathrm{Al}^{3+}$ site on the HMS surface plays an important role in the adsorption and stabilization of the incorporated flavylium.

The present study aims to find the method to let the anthocyanin be adsorbed efficiently on the mesoporous silica without any severe color turn and loss of stability. The effect of the solid acidity on the adsorption behavior and the stability was investigated by adding $\mathrm{Al}^{3+}$ to the HMS. In addition, the effect of the hydrophobicity in 
the pore environment was examined by modifying the inner pore wall of the HMS by alkyl chain groups. Photo-fading of each sample was measured under visible light irradiation to check whether the stability of the anthocyanin was influenced by the modification of the HMS to increase the amount of the adsorbed dye.

\section{Experimental}

\subsection{Materials}

Anthocyanin (AN) was purchased from Kanto Chemical as "Grape Skin Color" and used as received.

The HMS type mesoporous silica was synthesized following the method described elsewhere $[15,16]$. Briefly, tetraethoxysilane and dodecylamine, both supplied from Wako Chemical, were used as a silicon source and a structure-directing agent, respectively. An aqueous ethanolic solution of the dodecylamine $\left(0.91 \mathrm{~g}\right.$ in $40 \mathrm{~cm}^{3}$ water $/ 5 \mathrm{~cm}^{3}$ ethanol) was mixed with tetraethoxysilane $(4.6 \mathrm{~g})$ at $333 \mathrm{~K}$ and stirred for 1 day. The resulting sediment was collected by filtration and calcined at $903 \mathrm{~K}$ for $6 \mathrm{~h}$ under air stream. To prepare the Al-containing HMS, $0.12 \mathrm{~g}$ of $\mathrm{Al}\left(\mathrm{NO}_{3}\right) \cdot 9 \mathrm{H}_{2} \mathrm{O}$ supplied from Wako Chemical was blended to the solution of dodecylamine before mixing with tetraethoxysilane. The HMS samples containing aluminum are denoted as Al-HMS. The introduced amount of $\mathrm{Al}^{3+}$ was $1.5 \mathrm{~mol} \%$ to $\mathrm{Si}^{4+}$. The BET surface area of typical samples was greater than $800 \mathrm{~m}^{2} / \mathrm{g}$, and the samples had a narrow pore size distribution with the mean pore diameters in the range between 2.8 and $3.0 \mathrm{~nm}$.

Part of the obtained HMS samples was made hydrophobic by modifying the inner pore wall with $n$-propyltriethoxysilane, in a similar manner described in the literature [20]. Thus, $0.5 \mathrm{~g}$ of the HMS or Al-HMS was previously dried in an oven at $393 \mathrm{~K}$. The dried HMS or Al-HMS was mixed with $5 \mathrm{~cm}^{3}$ of toluene containing $0.10 \mathrm{~g}$ of $n$-propyltriethoxysilane, and then the mixture was refluxed for $6 \mathrm{~h}$ under nitrogen stream. The resulting sample was filtered, washed with toluene and acetone, and then dried under reduced pressure for $2 \mathrm{~h}$. Thus obtained hydrophobic HMS and Al-HMS are denoted as HMS(A) and Al-HMS(A), respectively.

\subsection{Sample preparation}

The synthesized HMS, Al-HMS, HMS(A) and Al-HMS(A) were all used as the host 
materials for the adsorption of AN. The composite of AN and each host materials was prepared as follows. The aqueous methanolic solution (water: methanol $=7: 3 \mathrm{v} / \mathrm{v}$ ) was used as a solvent of AN. The host material weighed $100 \mathrm{mg}$ was mixed with $100 \mathrm{~cm}^{3}$ of the aqueous methanolic solution containing $20 \mathrm{mg}$ of $\mathrm{AN}$, and then maintained at $278 \mathrm{~K}$ in the dark. After 3 days the mixture was filtered and the resulting sediment was dried in the air. The obtained composite sample is denoted as AN/HMS, AN/Al-HMS, AN/HMS(A) or AN/Al-HMS(A).

\subsection{Measurements}

The structure of the synthesized host materials was assured by XRD measurements. The XRD patterns were measured with Rigaku MiniFlex X-ray diffractometer $(\mathrm{CuK} \alpha$, step angle and scan speed $0.05^{\circ}$ and $2 \% \mathrm{~min}, 15 \mathrm{~mA}, 30 \mathrm{kV}$ ).

The amounts of the adsorbed anthocyanin on each sample were estimated from the optical absorption of the dye in the diffuse reflectance UV-Vis spectra. The UV-Vis spectra were collected with JASCO V-550 spectrophotometer equipped with ISV-469 integrating sphere.

To investigate the light endurance of the composite samples, the color fading caused by visible light irradiation was evaluated from the decrease in the absorption in the diffuse reflectance spectra. A $100 \mathrm{~W}$ halogen lamp (Schott Megalight 100) equipped with a $30 \mathrm{~cm}$ length flexible light guide was used as a visible light source. The powder sample was loaded in a plastic cell covered with a thin glass, and placed at the position of $2 \mathrm{~cm}$ from the aperture of the light guide.

\section{Results and discussion}

\subsection{Structure of the synthesized mesoporous silica}

Figure 2 illustrates the XRD patterns of the HMS and Al-HMS samples. A peak at around $2 \theta=2^{\circ}$ was observed in both samples, indicating that the samples possessed the wormhole type mesopore, as described in the literature [21]. The formation of the uniformed mesopore was thought to be partially obstructed by the addition of heterogeneous atoms $\left(\mathrm{Al}^{3+}\right)$, because the peak intensity of Al-HMS was a little weaker than that of HMS. The loss of the regularity in the mesostructure by the addition of $\mathrm{Al}^{3+}$ has also been reported on other mesoporous silicas such as MCM-41[22] and 
FSM-16[23]. However, as the decrease in the peak intensity was small, the extent of the loss of regularity was expected to be negligible in the following experiments.

\subsection{Adsorption of anthocyanin onto the mesoporous silica}

Figure 3 illustrates the diffuse-reflectance UV-Vis spectra of the composite samples. As shown in Figure 3(a), the spectrum of AN/HMS has very low absorption peak at 530 nm. This means that the AN/HMS sample only exhibited extremely pale color and that the amount of adsorbed AN was small on the pure HMS. On the other hand, the addition of $\mathrm{Al}^{3+}$ to the HMS made the color of the sample strong, as shown in Figure 3(b). Therefore, the addition of $\mathrm{Al}^{3+}$ was found to be beneficial for the better adsorption of $\mathrm{AN}$ on HMS. It has been known that the addition of small amount of $\mathrm{Al}^{3+}$ to mesoporous silicas results in the formation of an acidic site, because the shortage of electric charge is caused by the partial substitution of $\mathrm{Si}^{4+}$ by $\mathrm{Al}^{3+}$ in the silica framework [23]. We have already confirmed the formation of an acidic site by the contamination of $\mathrm{Al}^{3+}$ to mesoporous silicas [15]. As the anthocyanin is a cationic and basic natural dye, it seems that the negative charge of the acidic site urged the adsorption of AN on the HMS. In addition, from Figure 3(a) and (b) we can see that the peak shifted to longer wavelength of $548 \mathrm{~nm}$ on the AN/Al-HMS. As a consequence of the peak shift, the AN/Al-HMS sample looked a little purplish, but the color change was small to the eye. The bathochromic shift of anthocyanin is generally known to reflect the interaction with metal ions such as $\mathrm{Al}^{3+}, \mathrm{Fe}^{3+}$ or $\mathrm{Mg}^{2+}$ [24-26]. Taking these into consideration, the bathochromic shift seen in the AN/Al-HMS further supports that the enhancement of the AN adsorption was caused by the interaction between the dye and the $\mathrm{Al}^{3+}$ site on the HMS surface.

The hydrophobization of the mesoporous silicates by modifying the surface with alkyl chains using $n$-propyltriethoxysilane had some effect on the amount of the adsorbed AN. The adsorption of AN on HMS was not prompted by the hydrophobization, since the absorption of $\mathrm{AN} / \mathrm{HMS}(\mathrm{A})$ was almost the same as that of AN/HMS, as shown in Figure 3(c). On the other hand, Figure 3(b) and (d) show that the amount of adsorbed AN on Al-HMS(A) was quite larger than that on AN/Al-HMS. These results mean that the hydrophobization itself was not effective for the adsorption of AN, whereas the modification with the alkyl chains had a remarkable effect on the adsorption of $\mathrm{AN}$ on the $\mathrm{Al}^{3+}$ site and helped increase the amount of adsorbed $\mathrm{AN}$. We 
tentatively think that the coordination of $\mathrm{AN}$ to $\mathrm{Al}^{3+}$ might be so strong that only limited amount of AN molecule could access to the $\mathrm{Al}^{3+}$ site, and that the existence of the alkyl groups around the $\mathrm{Al}^{3+}$ site might inhibit an excessive interaction between the $\mathrm{Al}^{3+}$ site and the AN molecule. This hypothesis is further suggested by the shift of the absorption peak. As described above, the AN adsorbed on the HMS exhibited its peak at $530 \mathrm{~nm}$, and the peak shifted to $548 \mathrm{~nm}$ on AN/Al-HMS. In the spectrum of AN/Al-HMS(A), the absorption peak was found at $542 \mathrm{~nm}$, which was slightly red-shifted compared to AN/Al-HMS. This result implies that the interaction between $\mathrm{Al}^{3+}$ site and the AN molecule was weakened by the hydrophobization.

\subsection{Photostability of the anthocyanin in the composite samples}

The stability of the various AN/HMS samples under visible light irradiation was investigated. Figure 4 illustrates the spectral changes of a typical composite sample, AN/Al-HMS(A) during visible light irradiation from the 100 W halogen lamp. Monotonous decrease in the absorbance of the main peak was observed along with the irradiation, indicating that simple degradation of AN occurred. The bleaching of AN under ambient condition is considered to be the destruction of the chromophore ring by the oxidation. The same tendency was also observed in the spectral changes of all other samples than AN/Al-HMS(A) under the irradiation.

Figure 5 shows the difference in the stability of AN adsorbed on various host materials. Gradual decrease in the color of AN was observed on all samples under the irradiation. The degree of the fading was smallest on AN/Al-HMS, indicating that the addition of $\mathrm{Al}^{3+}$ to HMS had positive effect on the fastness of AN against visible light, although the difference in the stability was not so large from other samples. However, the stabilization effect was perfectly lost by the hydrophobization of Al-HMS, although larger amount of AN was adsorbed on Al-HMS(A) than Al-HMS, as described above. From these results, we concluded that the acidic and electrostatic properties caused by the $\mathrm{Al}^{3+}$ contributed to the stabilization of $\mathrm{AN}$ on Al-HMS, and that the hydrophobization of Al-HMS hindered the stabilization effect on the AN molecule by the $\mathrm{Al}^{3+}$ site. The effect of $\mathrm{Al}^{3+}$ in the inorganic host materials on the immobilization and stabilization of natural betalain and another synthetic dye has also been reported [6, $27,28]$, and the present result was in accordance with the previous reports.

The $n$-propyltriethoxysilane has been reported to be immobilized through the surface 
hydroxyl group of the HMS [29]. On the other hand, the addition of $\mathrm{Al}^{3+}$ to silicates causes the formation of the hydroxyl group working as Brønsted acid sites. Accordingly, immobilization of the $n$-propyltriethoxysilane on the $\mathrm{Al}^{3+}$ site might preferably take place, resulting in the decrease in the acidic and electrostatic effects caused by the $\mathrm{Al}^{3+}$ site, as well as in the steric hindrance of the $\mathrm{Al}^{3+}$ site from the AN molecule.

\subsection{Adsorption behavior of the anthocyanin on HMS}

We have reported that the incorporation in the mesoporous silicates has an enormous effect on the stabilization of the adsorbed synthetic flavylium dye, an analogue of the natural anthocyanin $[15,16]$. The natural anthocyanin has also been stabilized by the intercalation in the clay interlayer [7]. In those prior researches, the color fading of the incorporated dye has practically been suppressed even under irradiation. We have reached the conclusion that the inhibition of the contact with atmospheric oxygen molecule is one of the reasons of the stabilization of the dye molecules shielded in the inorganic host materials.

In the present study, the stabilization effect was indeed seen on AN/Al-HMS, however, the degree of the stabilization was not so large as expected from the previous investigations. As described above, the stabilization of AN on Al-HMS may surely be brought about by the interaction with the $\mathrm{Al}^{3+}$ site. Although we do not have a clear answer to the reason why the stabilization effect on AN was not so significant, we think that the inferiority of the stabilization effect of AN to the synthetic flavylium dye may stem from the difficulty in the incorporation of the AN molecules deep inside the mesopore. Since the polarity of the AN molecule is different from that of the flavylium, the affinity of the AN molecule to the environment inside the mesopore may be weaker than that of the flavylium. Steric effect may be another possible reason: as the AN possesses a bulky sugar moiety in its molecular structure, the diffusion of the dye into the inner part of the mesopore is more difficult than the flavylium, having slim molecular structure.

The $\mathrm{Al}^{3+}$ site of the Al-HMS existed on the outer surface or inside the mesopore near the external surface, as well as the inner pore wall. The electrostatic interaction between the $\mathrm{Al}^{3+}$ near the surface and AN might cause the increase in the adsorbed AN, together with the enhancement of the stability, as described in section 3.3. The hydrophobization of the Al-containing HMS by the alkylsilane presented more optimized environment for 
1 the adsorption of AN. Thus, the hydrophilic part of the anthocyanin molecule (i.e., 2 hydroxyl groups and sugar moiety) approached to the $\mathrm{Al}^{3+}$ site, while the hydrophobic 3 part was protected by the alkyl groups near the $\mathrm{Al}^{3+}$ site. Although water-soluble, the $4 \quad$ AN molecule is reported to have rather hydrophobic character, with the 1-octanol/water 5 partition coefficient $\left(P_{\text {ow }}\right)$ greater than one [30]. Therefore, it is not surprising that the 6 hydrophobization of HMS contributed to the increase in the adsorption of AN. In the 7 AN/Al-HMS(A), the polar part of the anthocyanin may work as the anchor for the immobilization on the surface of the Al-HMS, whereas the lipophilic property of AN may be avoided by the alkyl chain, resulting in the adsorption of large amount of AN.

\section{Conclusion}

Natural anthocyanin can be efficiently adsorbed on HMS type mesoporous silica both by introducing $\mathrm{Al}^{3+}$ to the HMS and by making the surface more hydrophobic. The effect of the immobilization of the dye on the stability enhancement against irradiation is limited, perhaps because the dye molecule is not adsorbed in the internal sphere of the mesopore. It is suggested that the adsorption of the dye deep inside the pore may help improving the light fastness of the adsorbed dye molecule.

\section{Acknowledgment}

Part of this work was financially supported by Cosmetology Research Foundation, Suga Weathering Technology Foundation, and Ministry of Education, Culture, Sports, Science and Technology (Grant-in-Aid for Scientific Research \#22360330 and \#24700787). 


\section{References}

[1] K. Yoshida, M. Mori, T. Kondo, Nat. Prod. Rep., 26 (2009) 884-915.

[2] R. Brouillard, S. Chassaing, A. Fougerousse, Phytochemistry, 64 (2003) 1179-1186.

[3] A. Castañeda-Ovando, M.d.L. Pacheco-Hernández, M.E. Páez-Hernández, J.A. Rodríguez, C.A. Galán-Vidal, Food Chem., 113 (2009) 859-871.

[4] R.N. Cavalcanti, D.T. Santos, M.A.A. Meireles, Food Res. Int., 44 (2011) 499-509.

[5] G. Mazza, R. Brouillard, Food Chem., 25 (1987) 207-225.

[6] E. Lima, M.J. Martinez-Ortiz, E. Fregoso, J. Mendez-Vivar, Z.G.J.C. Ruren Xu, Y. Wenfu, Stud. Surf. Sci. Catal., Elsevier, 2007, pp. 2110-2115.

[7] Y. Kohno, R. Kinoshita, S. Ikoma, K. Yoda, M. Shibata, R. Matsushima, Y. Tomita, Y. Maeda, K. Kobayashi, Appl. Clay Sci., 42 (2009) 519-523.

[8] A.A. Teixeira-Neto, C.M.S. Izumi, M.L.A. Temperini, A.M.D. Ferreira, V.R.L. Constantino, Eur. J. Inorg. Chem., (2012) 5411-5420.

[9] O. Belhadj Miled, D. Grosso, C. Sanchez, J. Livage, J. Phys. Chem. Solids, 65 (2004) 1751-1755.

[10] H. Tanaka, T. Usui, S. Sugiyama, S. Horibe, H. Shiratori, R. Hino, J.Colloid Interface Sci., 291 (2005) 465-470.

[11] Y. Tozuka, S. Sasaoka, A. Nagae, K. Moribe, T. Oguchi, K. Yamamoto, J. Colloid Interface Sci., 291 (2005) 471-476.

[12] Z. Mehraban, F. Farzaneh, Microporous Mesoporous Mater., 88 (2006) 84-90.

[13] P.T. Tanev, T.J. Pinnavaia, Science, 267 (1995) 865-867.

[14] F. Pina, M.J. Melo, C.A.T. Laia, A.J. Parola, J.C. Lima, Chem. Soc. Rev., 41 (2012) 869-908.

[15] Y. Kohno, S. Tsubota, Y. Shibata, K. Nozawa, K. Yoda, M. Shibata, R. Matsushima, Microporous Mesoporous Mater., 116 (2008) 70-76.

[16] Y. Kohno, M. Senga, M. Shibata, K. Yoda, R. Matsushima, Y. Tomita, Y. Maeda, K. Kobayashi, Microporous Mesoporous Mater., 141 (2011) 77-80.

[17] Z. Gabelica, S. Valange, M. Shibata, H. Hotta, T. Suzuki, Microporous Mesoporous Mater., 44-45 (2001) 645-652.

[18] T. Itoh, K. Yano, Y. Fukushima, J. Am. Chem. Soc., 124 (2002) 13437-13441. 
1 [19] G. Berlier, L. Gastaldi, E. Ugazio, I. Miletto, P. Iliade, S. Sapino, J. Colloid 2 Interface Sci., 393 (2013) 109-118.

3 [20] K. Shimizu, E. Hayashi, T. Hatamachi, T. Kodama, T. Higuchi, A. Satsuma, Y.

4 Kitayama, J. Catal., 231 (2005) 131-138.

5 [21] N. Marín-Astorga, G. Pecchi, T.J. Pinnavaia, G. Alvez-Manoli, P. Reyes, J. Mol.

6 Catal. A: Chem., 247 (2006) 145-152.

7 [22] Z.H. Luan, C.F. Cheng, W.Z. Zhou, J. Klinowski, J. Phys. Chem., 99 (1995)

$8 \quad 1018-1024$.

9 [23] S. Inagaki, Y. Yamada, Y. Fukushima, Stud. Surf. Sci. Catal., 105 (1997)

$10 \quad 109-116$

11 [24] T. Goto, T. Kondo, Angew. Chem. Int. Ed. Engl., 30 (1991) 17-33.

[25] M.C. Moncada, S. Moura, M.J. Melo, A. Roque, C. Lodeiro, F. Pina, Inorg. Chim. Acta, 356 (2003) 51-61.

14 [26] S. Kunsági-Máté, E. Stampel, L. Kollár, M.S. Pour Nikfardjam, Food Res. Int., 41 15 (2008) 693-696.

16 [27] H. Laguna, S. Loera, I.A. Ibarra, E. Lima, M.A. Vera, V. Lara, Microporous 17 Mesoporous Mater., 98 (2007) 234-241.

18 [28] E. Lima, P. Bosch, S. Loera, I.A. Ibarra, H. Laguna, V. Lara, Appl. Clay Sci., 42 19 (2009) 478-482.

20 [29] T. Yanagisawa, T. Shimizu, K. Kuroda, C. Kato, Bull. Chem. Soc. Jpn., 63 (1990) $21 \quad 1535-1537$.

22 [30] L. Müller, P. Bednar, P. Bartak, K. Lemr, J. Sevcik, J. Sep. Sci., 28 (2005)

23 1285-1290. 
3 Figure 1. Typical structure of anthocyanin (Malvidin-3-glucoside). The thick line 4 indicates the flavylium skeleton.

5

6 Figure 2. XRD patterns of the (a) HMS and (b) Al-HMS samples.

7

8 Figure 3. Diffuse-reflectance UV-Vis spectra of various AN/HMS samples. (a)

\section{Figure Captions}

AN/HMS, (b) AN/Al-HMS, (c) AN/HMS(A) and (d) AN/Al-HMS(A).

Figure 4. Changes in the diffuse-reflectance spectra of the AN/Al-HMS(A) sample during visible light irradiation for $240 \mathrm{~min}$. Irradiation times were 0, 30, 60, 120, 180 and $240 \mathrm{~min}$.

Figure 5. Changes in the AN absorption value at $\lambda_{\max }$ of (a) AN/Al-HMS, (b) AN/HMS, (c) AN/Al-HMS(A) and (d) AN/HMS(A) under continuous irradiation. The stability of AN in the samples is expressed by $A / A_{0}$, where $A_{0}$ and $A$ indicate the absorption before irradiation and at the given time after starting irradiation, respectively.

(19) 


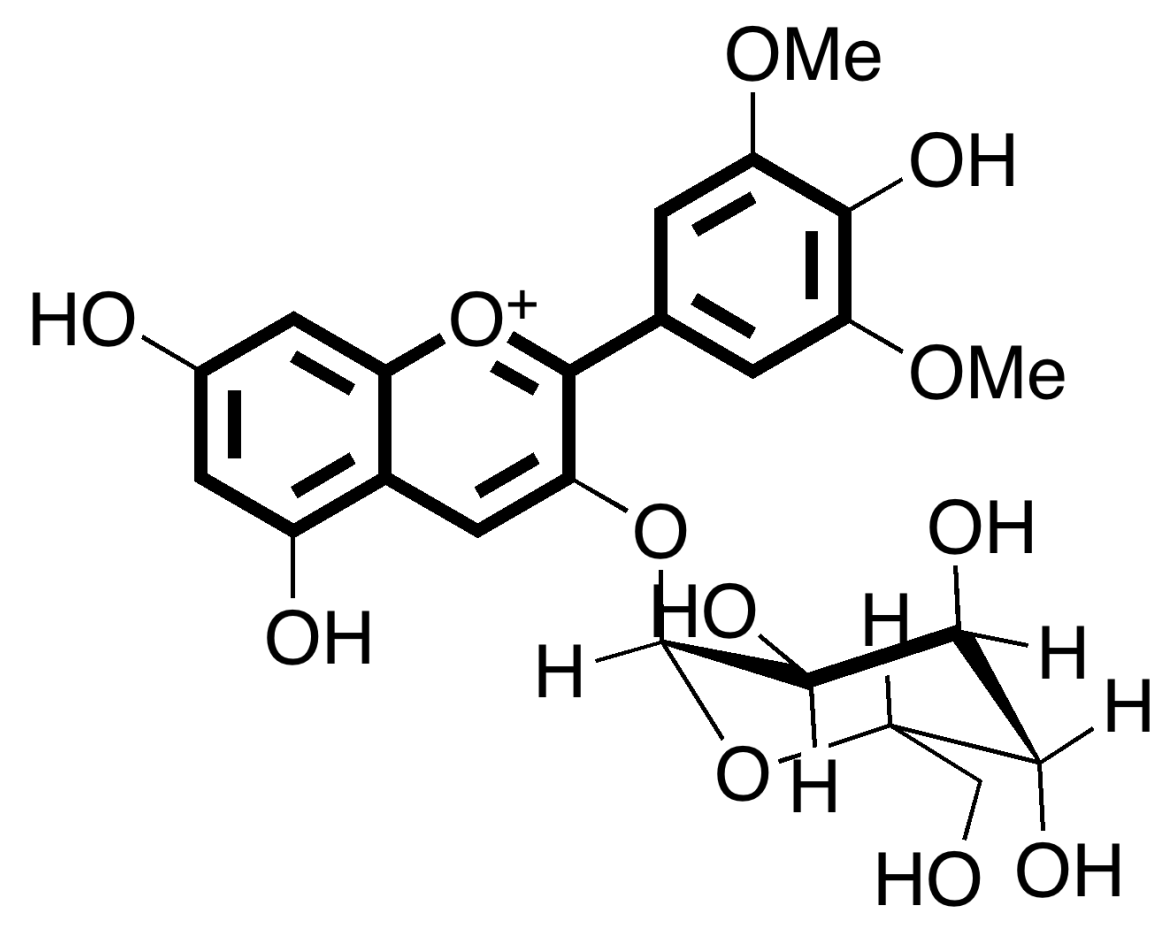




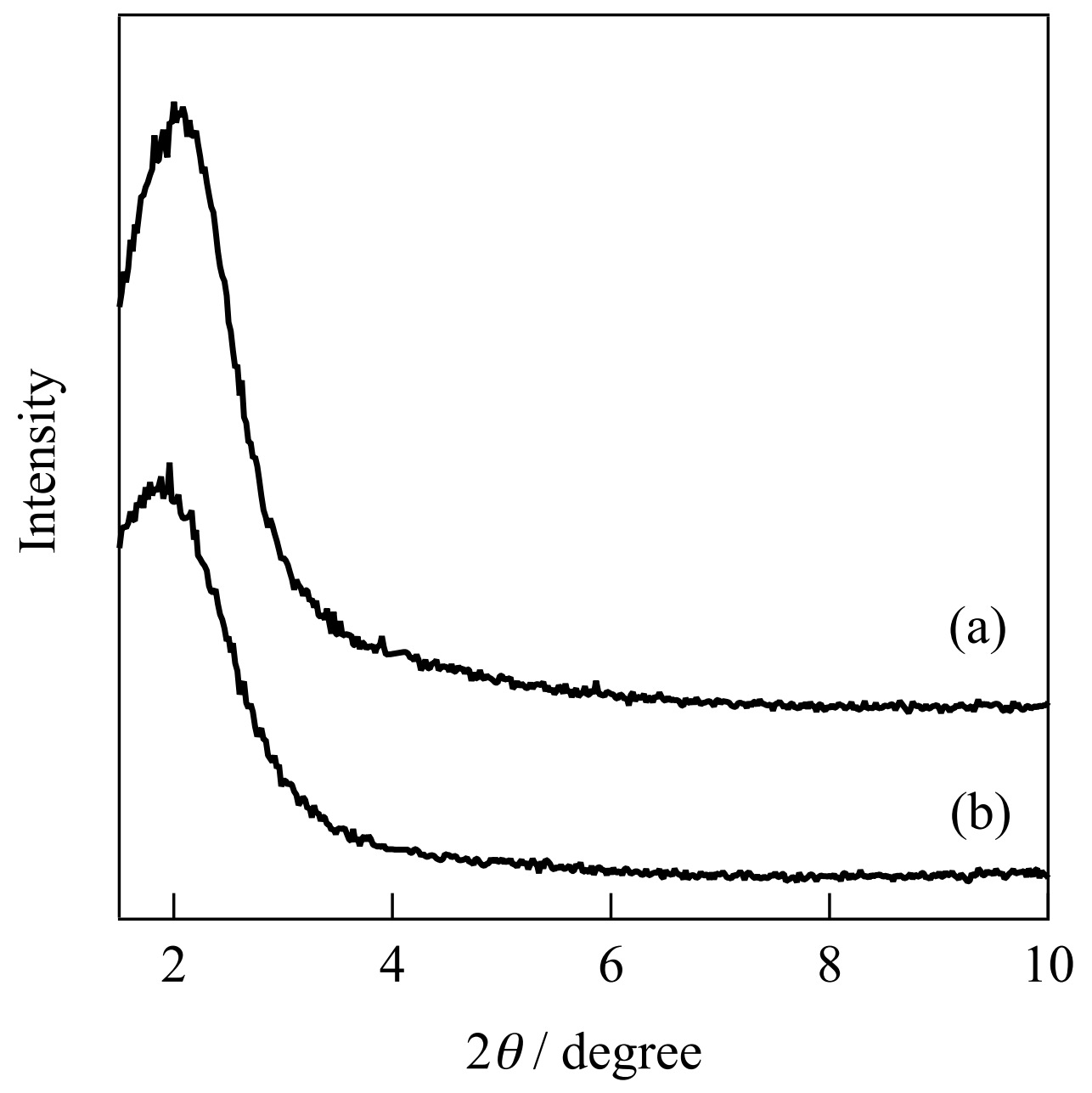

Figure 2 


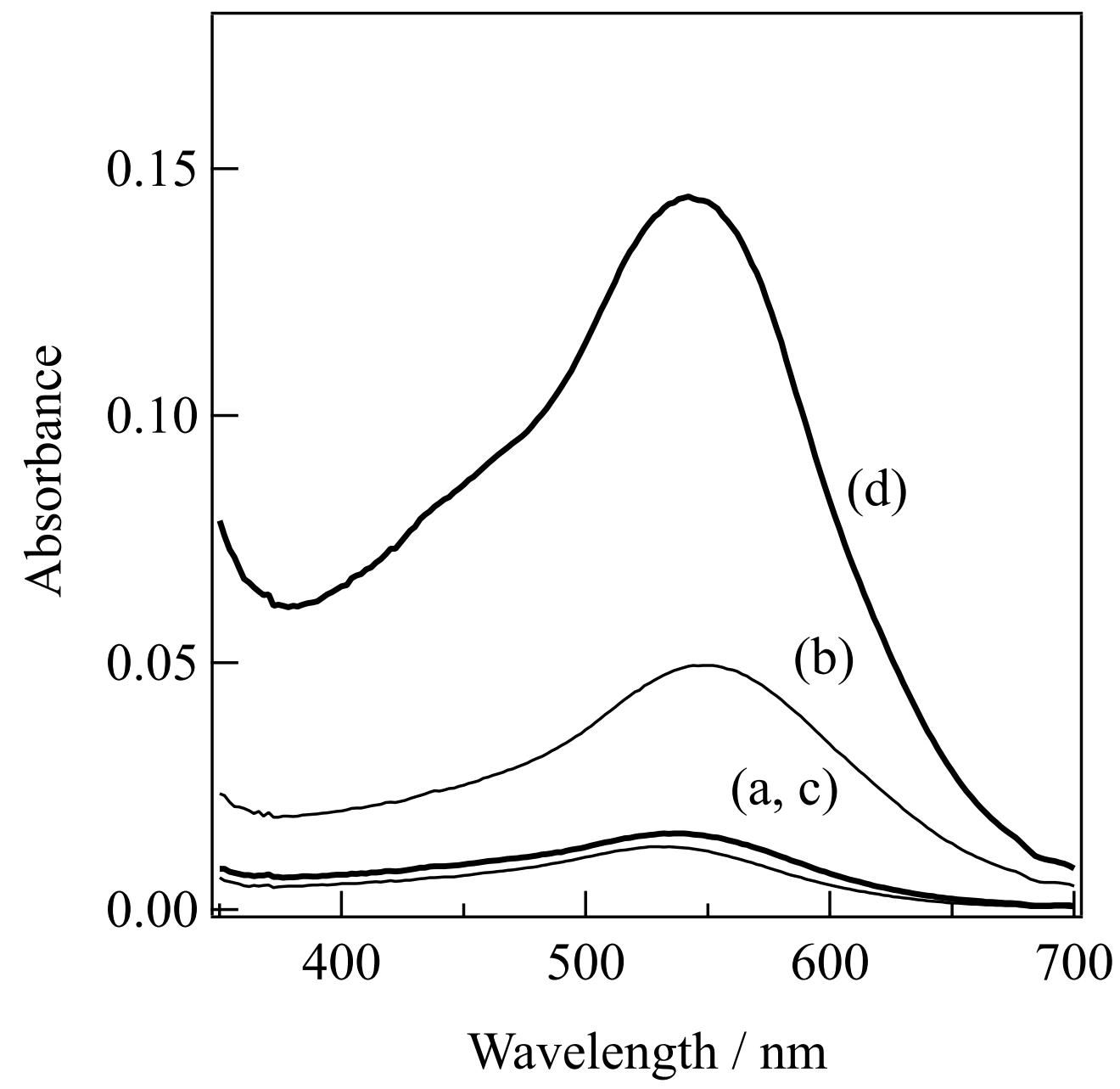




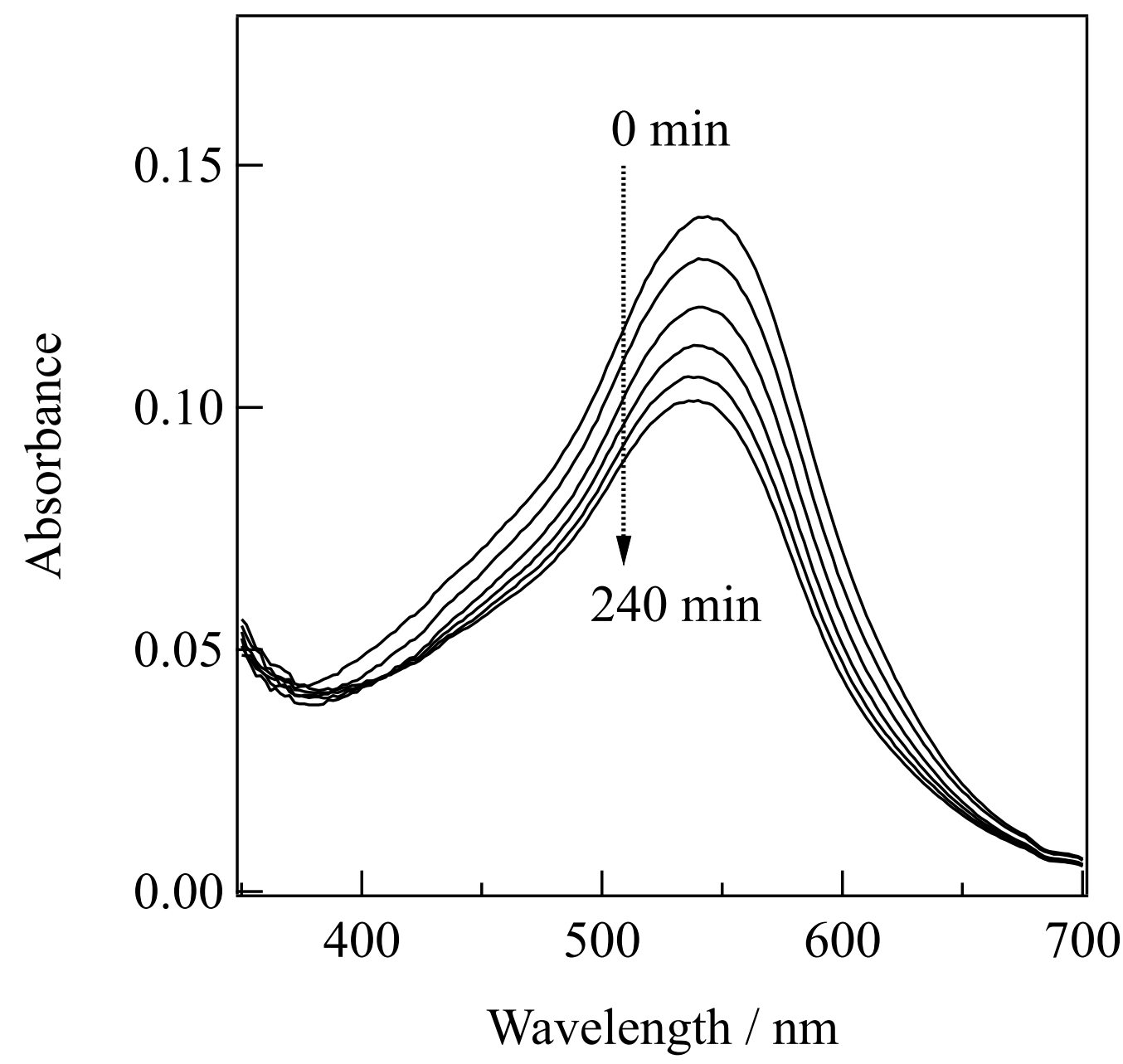

Figure 4 


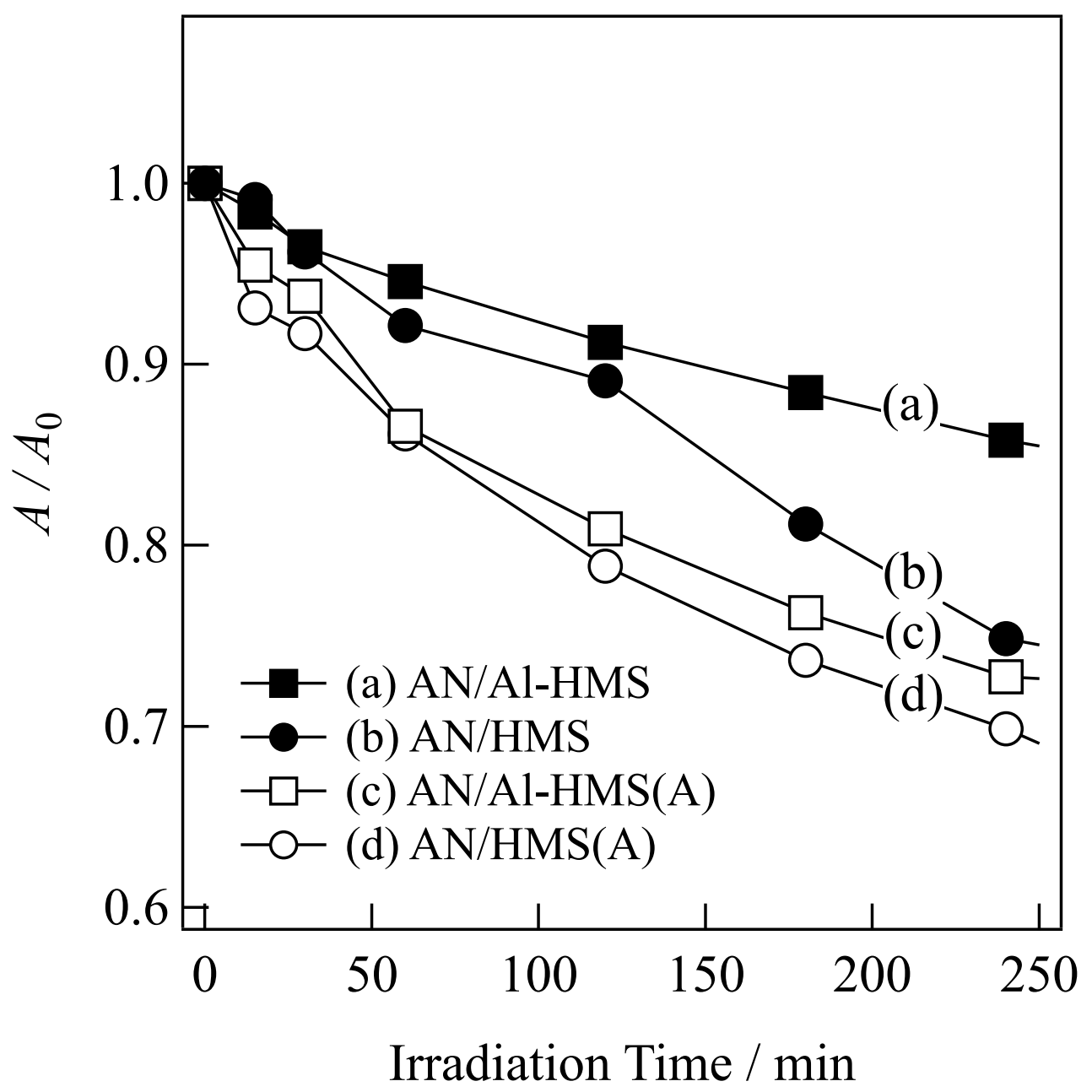

